enernata is as applicable to one sort of enema as to another, and not, as some nurses seem to think, merely to the nutrient.

Furthermore, I heard a nurse speak of "catherizing a patient!"

I must confess that these indications of poor intellectual training make me feel ashamed. Every nurse among us should take pride in using correctly the technical words that helong to our work. If we are careless we bring upon our whole profession the reproach of unintelligence.

$\mathbf{x}$.

\title{
REGISTRATION OF CERTIFICATES
}

Dear Editor: I would like to ask through the Journal why we registered nurses are expected and requested to record our certificates every three years, or, indeed, why once is not sufficient. The doctors register but once.

Before we were given the right to register we were told that " nurses might have a professional degree given hy the state as well as doctors;" now many of us are wondering why we must, unlike them, periodically record our certificates. Other legal documents do not require to be so dealt with-why these? Besides it is most inconvenient to attend to this at the time required, if one is out of town. An explanation will be appreciated.

E. L. $P$.

[The provision in the New York law requiring registration of certificates every three years was inserted in the original hill on the recommendation of a number of prominent officials of the New York Mcdical Society as a safeguard against theft, or the appropriation of registration certificates after death, as has been known to frequently occur in the medical profession. It is supposed to give the nurses greater protection than thc doctors have.-ED.]

\section{MISSIONS TO LEPERS}

Dear Editor: The Journat of February has just come to me, out on a case in the country, and I noticed among other things the request for information ahout missions to lepers, where they are located, and if nurses are employed in the care of such patients. Allow me for to-day to give you the following hrief information.

The Moravian Church has, for more than forty years, carried on the work of caring for lepers in Jerusalem, and since the early eighties nursing sisters of the Moravian Deaconess' Home of Neisky, Germany, have been employed in the care of these patients. At present, four sisters, with an adequate staff of helpers, are taking care of from fifty to sixty of the poorest of the poor at the hospital "Jesus Hilfe," Jerusalem. At "Bethesda," Paramaribo, Surinam, four other sisters of the same institution are taking care of the same class of patients; this work is of more recent date.

In Central Africa, the Moravian Church has occasion to care for lepers, although here there is not yet a regularly established hospital for them.

In Western Himalaya, in connection with the regular hospital work at Leh, Ladakh, these patients come under their care, and I, myself, as missionary nurse have taken care of several, while engaged in the work out there. The state hospital for lepers of Kashmir is under the supervision of the well-known Doctors A. and F. Neve, medical missionaries at Srinigar, and though here no actual trained European nurses are employed, their infiuence is made to bear upon the whole institution. 
There is one large haspital colony for lepers in the south of India, at Puriella, under the care of the Gosner Mission. It has a European doctor at its head, but $I$ do not think he has any European assistants in the nursing staff. There are other similar missionary institutions in India, but I cannot give full information about them.

If the above information will help to make the noble work which has been carried on by the different missionary societies more widely known, I shall indeed be pleased. May it also put into the hearts of many a desire to support the work by earnest prayer and contributions, which are always greatly needed to successfully carry on the work.

1. 8 .

[This letter came to the editorial office in a roundabout way, which has made it impossible to communicate with the writer and obtain a correct reading of some of the proper names about which there is doubt. 'The information is too interesting to omit on this account. The nurse who made the inquiry for information about work among the lepers wishcd, we think, to find a place where a nurse nuight offer herself for such work, so we specially desire information of a place where nurses are needed to help care for lepers.-ED.]

\section{DI8POSAL OF REFUSE}

Dear Edtor: I am beginning to be puzzled as to how nurses are to dis. pose of soiled dressings in apartments, where, during the summer, there is no fire in the basement, and none but gas stoves in the apartments. Will nurses who have solved the problem kindly help out those who have not.

E. L. P.

Treatment of Frat-Foot.-Schanz calls attention to the fact, which has been generally overlooked hitherto, that the arch of the foot is a transverse as well as a longitudinal arch. The transverse mechanism may be out of gear without disturbance of the longitudinal, or both may be involved. This is the explanation of the persistence of symptoms after correction of flat-foot: the transverse arch has not been corrected with the longitudinal. The disturbances in the transverse arch are experienced in the front part of the foot, and it spreads out abnormally wide; between the ball of the big toe and the ball of the little toe the distance is over a quarter of an inch wider than in the other foot. By strapping the foot with adhesive plaster to bend it into proper shape to restore the transverse arch, all disturbances vanish. He prefers for the purpose a strip of cotton flannel and Finck's glue. This makes a plaster that fits better and is more easily removed. The glue is made of 7 parts Venice turpentine, 6 parts mastic, 12 parts colophony, 4 parts white resin, and 90 parts 90 per cent. alcohol, mixed and filtered. A thin layer of this mucilage is spread over the foot, and the fuzzy side of the cotton flannel adheres flrmly to it. He regards this combination of glue and cotton flannel as a marked advance in the technic of such dressings. He also gives an illustrated description of a durable leather device to wear to sustain both the longitudinal and the transverse arch.-Journal American Medical Association. 